\title{
JÜRGEN HABERMAS, DEMOCRACIA, INCLUSIÓN DEL OTRO Y PATRIOTISMO CONSTITUCIONAL DESDE LA ÉTICA DEL DISCURSO
}

\author{
JURGEN HABERMAS: DEMOCRACY, INCLUSION OF THE OTHER AND \\ CONSTITUTIONAL PATRIOTISM FROM THE ETHICS OF THE SPEECH
}

Fecha de Recepción: 02/05/2011

Fecha de Aceptación: 14/05/2011

Jorge Araya Anabalón ${ }^{1}$

Resumen:

El presente trabajo sobre la ética del discurso de Jurgen Habermas, da cuenta de las connotaciones y exigencias para una democracia con legitimidad política y moral en nuestra sociedad. Entendiendo que una democracia radical no es algo dado por una sola vez y para siempre, sino el resultado de un proceso comunicativo que permite articular intereses distintos, donde están en juego la identidad, la solidaridad, la inclusión del "otro" y el patriotismo constitucional, entre otras cosas. Es decir, se puede corregir y recuperar el ideario normativo de la democracia moderna reduciendo la hegemonía de la racionalidad instrumental.

Palabras claveDemocracia, identidad, ética del discurso, patriotismo.

\begin{abstract}
This paper about Jurgen Habermas, discourse ethics deals with the connotations and exigencies for a democracy with political legitimacy and moral content for our society. Understanding that a radical democracy isn't found only once and forever, far from that, it is the result of a communicational progress that allows conjugation different interests, where identity, the solidarity, the inclusion of the other and the constitutional patriotism are present among other things, I mean, you can correct and recover the normative ideas of modern democracy by reducing the hegemony of the instrumental rationalization.
\end{abstract}

Key words:Democracy, identity, ethics of the speech, patriotism. 


\section{Modernidad y democracia en sociedades complejas}

Para Habermas, existe la posibilidad concreta de desarrollar una praxis que transforme la realidad y logre corregir las distorsiones de la modernidad. Su optimismo se sustenta en la existencia de una potencialidad de emancipación, expresado en un malestar de la ciudadanía que da cuenta de los diversos movimientos que lleva adelante la sociedad civil. Ahora, este cambio se realizará en el contexto de las democracias constitucionales, teniendo presente sus limitaciones, pero acentuando la dimensión moral de la democracia, a partir de las acciones comunicativas de la sociedad que se procedimentalizan en el ámbito del derecho².

Para Habermas ${ }^{3}$, la modernidad con sus insuficiencias, es un proyecto viable porque es un "proyecto inacabado", el cual puede corregirse a partir de una ética universalista de carácter dialógico ${ }^{4}$, donde la racionalidad y el lenguaje son puntos fundamentales de la mediación política, la cual puede llevarse a cabo en lo que él denomina una "democracia procedimentalista" 5 . Ahora, lo que justifica una democracia de este tipo son las pretensiones de validez que tiene una ética universalista, en la cual los derechos humanos y la justicia son la exigencia y fundamento del respeto a la dignidad humana, en la que destacan los derechos individuales.

\section{La concepción moral de la democracia}

La ética discursiva contiene una concepción dialógica de la democracia, coincidente con la percepción moral del constitucionalismo democrático, que a partir de su sistema normativo busca terminar con la marginación y la injusticia que se da en el sistema social. Para esto, es necesario que la acción comunicativa pueda encontrar una traducción jurídica ${ }^{6}$, donde el derecho se transforma en un espacio transformador de las demandas que surgen desde el sistema social, para convertirse en una norma que obliga al sistema político y a la burocracia a darles respuesta ${ }^{7}$. Dicho proceso se establece en el marco del Estado democrático, vinculándose jurídicamente y dando paso desde la solidaridad social a una solidaridad con valor moral. En este punto, la

2 Habermas, Jürgen, Sobre el desarrollo de las ciencias sociales y las ciencias del espíritu en la República Federal de Alemania, en J. Pérez (ed.), Textos y Contextos, Ariel, Barcelona, 1995, p. 23.

3 Habermas, Jürgen, Ensayos políticos, Península, Barcelona, 2000.

4 Habermas, Jürgen, Conciencia moral y acción comunicativa, Península, Barcelona, 1998.

5 Habermas, Jürgen, Facticidad y validez. Sobre el derecho y el Estado democrático de derecho en términos de teoría del discurso, Trotta, Madrid, 1998.

6 Habermas, Jürgen, Facticidad y validez. Sobre el derecho y el Estado democrático de derecho en términos de teoría del discurso, obr. cit. p. 199.

$7 \quad$ Ibíd. pp.146-245. 
ética discursiva daría cuenta de una "fundamentación moral"8, para que la democracia logre desarrollarse en el Estado de derecho, siendo la legalidad un fundamento "constituyente" de legitimidad moral.

Ahora bien, lo importante es que la ética del discurso, si bien no prescribe una forma particular de vida, sí hace posible que diferentes concepciones de ella puedan ser compatibles sin que por ello puedan eludir su capacidad crítica, la que comprende la pluralidad democrática en la sociedad civil.

\section{La solidaridad desde una concepción dialógica de la democracia}

Para Habermas ${ }^{9}$, en las sociedades complejas se forma una conciencia deliberativa de los ciudadanos, a partir del respeto a la soberanía popular y a los derechos humanos. Es de ahí donde nace la solidaridad abstracta y jurídicamente construida, la que es reproducida desde la deliberación política, aunque solo es posible a partir de la justicia de un sistema profundamente democrático el surgimiento de la solidaridad social.

La solidaridad, para Jurgen Habermas, es fundamentalmente un vínculo social, donde la dimensión universalista ocupa el primer lugar, y tiene su raíz en la tradición socialista. De tal forma que la solidaridad con el individuo en particular, a un grupo étnico, o movimiento político, ocupa un segundo nivel. De ahí que Habermas, desde la teoría de la acción comunicativa, distingue dos niveles: el primero como sistema, el segundo como mundo de la vida, lo cual refleja que la sociedad como un sistema es el resultado de acciones teleológicas (instrumentales o estratégicas) cuyo objetivo es el éxito, adecuando medios afines. Y en el caso del mundo de la vida, la sociedad se estructura comunicativamente, donde los individuos buscan el entendimiento por medio del diálogo y la cooperación para lograr acuerdos. Al considerar la sociedad como mundo de la vida, se está diciendo que es el lugar donde se establecen los vínculos de socialización e integración para el entendimiento. Así, la solidaridad ocupa un lugar destacado en la acción comunicativa, que es donde los individuos -sin ningún tipo de coerción- se reconocen como sujetos libres, solidarios y con competencia comunicativa que les permite fundamentar y responder sobre situaciones que les afectan.

De esta manera, la acción comunicativa es posible a partir de sujetos autónomos, donde su vinculación con el "otro" es inteligente y reflexiva, permitiéndoles actuar con su propia cosmovisión de mundo e identidad, sin tener que ocultarla para alcanzar una plena emancipación. Por otra parte, la acción comunicativa tiene como

8 Habermas, Jürgen, Escritos sobre moralidad y eticidad, Paidós / ICE-UAB, Barcelona, 1991, p. 131.

9 Habermas, Jürgen, La constelación postnacional, Paidós, Barcelona, 2000, p. 103. 
Jorge Araya Anabalón

núcleo central que los participantes se acepten recíprocamente como iguales -en los diferentes ámbitos de la acción comunicativa- y reconozcan la responsabilidad recíproca frente a los acuerdos logrados, los cuales siempre son revisables a partir de nuevas aportaciones. Esto pone de manifiesto una ética del reconocimiento mutuo de la diferencia a partir de la solidaridad, que puede ser universalizada, donde está presente la ilimitada comunidad de comunicación. Por otra parte, hay que considerar que todos los miembros de la sociedad civil moderna, sin importar lo que hayan sido, pasan a participar de una cultura política que resuelve los conflictos discursivamente.

De ahí que la propuesta de Habermas sea sobre un "Estado solidario" -concepto que no utiliza, pero que está implícito- con la aspiración de superar los intereses particularistas que van más allá del territorio, el grupo étnico o la religión. El Estado solidario es posible desde una conciencia dialógica que, partiendo de individuos a los que se les reconoce como interlocutores válidos, se establece una mediación política que pasa necesariamente por establecer relaciones de justicia (componente moral de una democracia avanzada). Ahora, una de las exigencias para que esta propuesta tenga éxito, dice relación con que los individuos establezcan acciones comunicativas coordinadas, que puedan ser traducidas a los diferentes órganos del sistema social para diseñar políticas públicas concretas.

\section{Reciprocidad y justicia en la acción comunicativa}

Habermas también hace una distinción, respecto a la reciprocidad, a partir de una "categoría pertinente al campo de la acción comunicativa" y otra desde el "principio de organización de los procesos de producción y reproducción social", dado que la diferencia entre la reciprocidad burguesa capitalista y la reciprocidad comunicativa, están dadas porque la burguesa es el libre intercambio de bienes entre iguales, contratantes o traficantes, bajo reglas contractuales que en el mejor de los casos puede lograr una cooperación por cierto interés. Por el contrario, la reciprocidad comunicativa, según Gabriel Amengual ${ }^{10}$, la constituye la misma acción comunicativa que no se sitúa en el nivel de intercambio o de las funciones que dan respuesta a la acción del primero; más bien se trata de un nivel primario y básico, que es la constitución de la comunicación, o sea que en la medida que es constitutiva de la comunicación, también lo es de los sujetos comunicantes. Digamos que la reciprocidad comunicativa no es condicional ni proporcional, por cuanto representa precisamente "una sali$\mathrm{da}$, y no una salida cualquiera, sino constitutiva del propio ser sujeto, que por lo mismo es un sujeto intersubjetivo o socializado. Significa, por tanto, ruptura del círculo cerrado contractualista y salida del solipsismo implicado"11. Es decir, la reciprocidad

10 Amengual Coll, Gabriel, La solidaridad según Jürgen Habermas /en/ Cuadernos Salmantinos de Filosofía, Nº 19, 1992.

11 Amengual Coll, Gabriel, obr. cit. p. 233. 
comunicativa es aquello que constituye el entendimiento o acuerdo (Verständigung), que se diferencia del acuerdo puramente fáctico del intercambio individualista.

En otro aspecto ${ }^{12}$, realiza una crítica respecto a Habermas, señalando que no existiría complementación entre justicia y benevolencia, debido a la antinomia entre la preocupación por el bienestar general, que es la justicia, y el bienestar del prójimo, que es singular (benevolencia). En definitiva, la solidaridad en Habermas privilegia el mantenimiento del conjunto social; aunque si bien se toca la ayuda al individuo particular necesitado, no es este el interés fundamental.

\section{La solidaridad en la diferencia cultural}

Habermas sostiene que la posición universal debe permitir la tolerancia, la solidaridad y la pluralidad de las identidades. Esto se puede lograr al ir más allá de las costumbres de la propia comunidad, sin que eso signifique desconocer dicho vínculo. En otras palabras, la solidaridad se desprendería de su carácter etnocéntrico al pasar a ser parte de una teoría universal de justicia, donde el discurso de la acción comunicativa vinculada al contexto, es ampliado al incluir a individuos con competencia comunicativa más allá de nuestras propias formas de vida particular. Por lo tanto, la solidaridad de la ética del discurso comprende la capacidad de identificarse con el "otro", quien debe tener las mismas posibilidades de articular sus necesidades y argumentos, al igual que exigimos que se nos otorgue a nosotros.

\section{Universalismo: superación de la visión nacionalista}

El universalismo de Habermas lo podemos entender como transcultural, lo que permite que la diferencia no sea una dificultad, sino una potencialidad que mediante un universalismo dialógico se transforma en el sustento moral, el cual permite superar la diferencia y las situaciones de conflicto. Recordemos que Habermas es antinacionalista en el sentido positivo, es decir, cuando se asocia a la identidad con un patriotismo nacionalista, versus un universalismo en un contexto de una ciudadanía universal que supera una visión étnica de la nacionalidad, pero también el relativismo universal ${ }^{13}$. Por lo mismo es que entiende que una verdadera mirada cosmopolita debe contemplar lo cultural, no eliminando las identidades culturales y teniendo como fondo el respeto a los derechos humanos.

12 Amengual Coll, Gabriel, obr. cit. pp. 235 -237.

13 Habermas, Jürgen, Facticidad y validez. Sobre el derecho y el Estado democrático de derecho en términos de teoría del discurso, obr. cit. 


\section{La crítica de Habermas al neoliberalismo}

Habermas sostiene que el neoliberalismo no tiene una mirada moral para tratar los derechos de las personas, las cuales son reducidas al espacio privado en su condición de clientes u oferentes. De esta forma, la praxis del modelo neoliberal reduce el campo de lo ético y de la política, dejando que la teoría económica se transforme en una dictadura incuestionable, como única mirada de la vida, prevaleciendo frente a las demandas éticas de las personas. Para Habermas, un modelo neoliberal no puede seguir administrando las relaciones sociales, por lo que es necesario dar paso a un liberalismo ético-político, que cambie la visión desde una racionalidad instrumental, estratégica o teleológica que ha sido sobredimensionada, a una razón dialógica que emancipe al hombre de todo dominio. Para Habermas, el poder económico y el poder político juegan un papel fundamental en la cohesión e integración de la sociedad, por lo cual debe haberse un control por parte de la ciudadanía junto al Estado, lo que obliga al reconocimiento de los diferentes niveles, generando una simetría en las relaciones sociales y produciendo una igual dignidad de las personas.

\section{Crítica a la lógica del modelo neoliberal}

Habermas hace una fuerte crítica al neoliberalismo por su radical conservadurismo, que se transforma en una regresión de muchos logros alcanzados, tanto en el aspecto social como en el cultural. Esto sucede a partir de una visión económica que impregna y coloniza todos los aspectos de la vida. Así, el dominio estratégico tecnológico tiene como fin alcanzar el crecimiento económico en función de la máxima utilidad material, donde todo se puede comprar y vender generando un atomismo social. En este sentido, el modelo neoliberal produce una distorsión que afecta a la organización sistémica de la sociedad respecto al mundo de la vida, que es lugar en el cual los seres humanos realizan sus actividades. El modelo económico coloniza todo el sistema social al someter nuestra existencia a las leyes estratégicas del mercado ${ }^{14}$. Esto se da porque el sistema social está formado, fundamentalmente, por dos niveles: el político y el económico. Ambos tienen lógicas independientes, pero generalmente el primero termina supeditándose al segundo, con lo cual el modelo económico impone la lógica del dinero y debilita al Estado y al sistema democrático, lo que termina con el sistema de seguridad social. Así, la colonización del mundo de la vida anula toda posibilidad de cooperación o solidaridad, generando una deshumanización a partir de un sistema que no produce equidad social y donde la competencia -a partir del egoísmo- genera riqueza. Los excluidos del sistema, por lo tanto, no existen o son una externalidad que no tiene mayor importancia.

\footnotetext{
14 Habermas, Jürgen, Teoría de la acción comunicativa, Taurus, Madrid, 1987, p. 469.
} 


\section{El proyecto de una democracia radical y dialógica}

El proyecto socialista de Habermas tiene una concepción ética que se aleja de la idea económica del marxismo y se afirma en la esfera del reconocimiento intersubjetivo, en que la dignidad inherente a la condición de persona humana está sustentada en la razón, la libertad y la reflexión como autonomía, lo que genera una democratización profunda de la sociedad civil y la ciudadanía. Habermas ha argumentado un proyecto de corte socialista que comprende una democracia radical ${ }^{15}$. Según José Pérez Tapias ${ }^{16}$, es un "socialismo factible" que, como radicalización de la democracia, busca en ella los objetivos de emancipación original que inspiraron el movimiento socialista. Con esto se pretende superar la instrumentalización de la democracia, por concepciones elitistas de la misma, y reafirmar que la democracia es un sistema político que puede ser perfeccionado, con la participación comprometida de todos los ciudadanos. Uno de los principios de este socialismo habermasiano, es la radicalización de la democracia, que incluye el respeto de las minorías a partir de reconocer la dignidad de cada individuo, aceptándolo como interlocutor válido desde la condición de ciudadano, que sería el núcleo moral de esta propuesta. Esta línea de acción está sustentada en un proyecto emancipador que busca la articulación de una vida digna, de acuerdo a criterios de justicia que puedan ser compartidos por todos. Es decir, deben respetarse las exigencias de universalidad, que tenga como objetivo discernir respecto a los intereses que se dan en el sistema social, con el fin de legitimar los que son prioritarios y afectan a más personas, para ser tratados políticamente.

En este caso, la radicalización de la democracia incluye una redistribución de la riqueza económica. Sin embargo, lo fundamental es la cuestión moral que va mucho más allá y que se expresa en una nueva acción comunicativa, cuyo objetivo es terminar con la alienación política que genera el sistema económico (fundamentalmente por una motivación al consumismo compulsivo), situación que lleva a los individuos a buscar un tipo de ciudadanía con marcados contenidos egoísta, y que reflejan los mecanismo del mercado ${ }^{17}$. Esta radicalización de la democracia, tiene la característica de ser dialógica y asimétrica, lo que permite el desarrollo de una ciudadanía crítica y solidaria, que genera nuevos procesos discursivos de participación de la sociedad civil en la política, para poder corregir las distorsiones de colonización del mundo de la vida que ha hecho el modelo económico neoliberal.

15 Cortina Orts, Adela, Ética aplicada y democracia radical, Tecnos, Madrid, 1993.

16 Pérez Tapias, José, El riesgo de opinar, Comares, Granada, 2006, pp. 443-444.

17 Habermas, Jürgen, Escritos sobre moralidad y eticidad, obr. cit. pp. 280-281. 
Jorge Araya Anabalón

\section{La emancipación social y la inclusión del "otro" desde la acción comunicativa}

Habermas percibe la lucha de las minorías étnicas por su reconocimiento como movimientos de emancipación y cree que:

"El desafío será mayor cuanto más profundas sean las diferencias religiosas, raciales o étnicas, o los desfases históricos-culturales que deben ser superados; será tanto más doloroso cuanto más las tendencias a autoafirmarse asuman un carácter fundamentalista que tienda a poner límites, ya sea porque la minoría que lucha por su reconocimiento, producto de su experiencia de impotencia, se bate en retirada, o porque, en primer lugar, debe despertar la conciencia a través de la movilización de masas"18.

Esta emancipación solo es posible realizarla sin violencia, en el contexto de las democracias constitucionales, teniendo presente sus limitaciones, pero acentuando la dimensión moral de la democracia a partir de las acciones comunicativas de la sociedad, que se procedimentalizan a partir del derecho ${ }^{19}$, en esta realidad política es posible pensar en la inclusión del "otro".

Para Habermas, el contenido racional de una filosofía moral basada en el respeto igualitario para cada individuo, descansa en una responsabilidad universal que cada uno tiene por el "otro". Por ello, Habermas plantea un universalismo sensible a la diferencia, donde el respeto a cada persona no comprende el asimilarla, sino que abarca a la persona del "otro", o de los otros en su alteridad. De esta manera, se formaliza una propuesta a cada ciudadano para que sea solidario, y responsable con los demás, situación que lleva a considerar a otras personas como uno de "nosotros", en el contexto de una comunidad más amplia.

Habermas considera que la comunidad moral comprende el término de la exclusión y la discriminación a partir de la incorporación de los marginados. De ahí que la comunidad deba ser abierta, y una de las posibilidades para lograr este objetivo estaría dado por la potencialidad de aplicar la teoría de la acción comunicativa, como una herramienta eficaz para buscar una solución a los problemas de los derechos humanos, la exclusión social de los individuos (que es la consecuencia de un modelo económico injusto), y a la necesidad de abrir un diálogo intercultural que dé paso a un nuevo universalismo que implique un nuevo orden mundial. Este nuevo universalismo de Habermas, lo podemos entender como transcultural, pues permite que la diferencia no sea una dificultad, sino una potencialidad. Por consiguiente, un univer-

\footnotetext{
18 Habermas, Jürgen, La inclusión del otro. Estudios sobre teoría política, Paidós, Barcelona, 1999, p.160.

19 Habermas, Jürgen, Sobre el desarrollo de las ciencias sociales y las ciencias del espíritu en la República Federal de Alemania, obr. cit. p. 23.
} 
salismo dialógico se transforma en el sustento moral que permite superar la diferencia y las situaciones de exclusión, conflicto social, y cultural.

Ahora, Habermas considera a la nación étnica junto a su ideología, como excluyente y chocante con el Estado nacional democrático, particularmente en referencia a los principios constitucionales republicanos que revelan el cómo enfrentar las situaciones postnacionales de socialización. De tal forma que el etnocentrismo étnico o nacionalista, supondría la negación de la acción comunicativa y por tanto la imposibilidad de una comunicación intercultural, dado que mantendría las relaciones asimétricas fomentando la inequidad. Para este autor es necesaria la intervención en los Estados nacionales cuando existe violación de los derechos humanos.

\section{Habermas y el reconocimiento cultural en la inclusión del otro}

Habermas sostiene que el reconocimiento (de derechos culturales) nace a partir de la "realización consecuente" de la declaración de los derechos individuales ${ }^{20}$. No obstante, la consideración que se requiere es una "incorporación sensible a las diferencias", por lo que se exige una separación entre el plano político-jurídico y la parte ética. Si bien es cierto que los grupos y subculturas se integran desde una perspectiva ética con su respectiva identidad colectiva, la integración política se realiza en una esfera más abstracta, como inclusión ciudadana ${ }^{21}$, lo que implica no solo una integración de tipo formal, sino moral, dado que las normas jurídicas tienen esa cualidad.

Podemos admitir, siguiendo a Habermas, que el fundamento de la inclusión del otro, y por cierto de la ciudadanía, es la forma del consenso respecto a los procedimientos que nos presentan los principios universalistas del Estado de derecho. Estos incluyen lo que Habermas denomina la cultura política de los principios democráticos, que se manifiesta en el llamado patriotismo de la Constitución (Verfassungspatriotismus) 22 . Habermas considera que la inclusión del "otro" debe comprenderse en la relación con la noción de la ciudadanía (que se vincula a una cultura política universalista), no obstante no se puede sobrepasar los derechos individuales de los ciudadanos que están plasmados en los derechos humanos, y son el fundamento del Estado de derecho democrático. Además, debemos considerar que cualquier orden jurídico representa nociones de vida particular y no solo derechos universales.

\footnotetext{
20 Habermas, Jürgen, Facticidad y validez. Sobre el derecho y el Estado democrático de derecho en términos de teoría del discurso, obr. cit. p. 43.

21 Ídem, p. 262.

22 Ídem, p. 264.
} 
Para este autor, esta situación se refleja en el problema de las identidades individuales que siempre están vinculadas con las identidades colectivas, las cuales logran su equilibrio a partir de una red cultural cohesionada, que no es otra que una cultura política que debe dar cuenta del bien común. Esto se refleja cuando sostiene que:

“... la coexistencia en igualdad de derechos de diferentes comunidades étnicas, grupos lingüísticos, confesiones y formas de vida no puede conseguirse al precio de la fragmentación de la sociedad. El doloroso proceso de desacoplamiento no puede desgarrar a la sociedad en una pluralidad de subculturas que se aíslen unas de otras. Por un lado, la cultura mayoritaria tiene que desprenderse de su fusión con la cultura política general, compartida en igual grado por todos los ciudadanos. De otro modo, dictaría desde el principio los parámetros de los discursos de autoentendimiento (...) Por otra parte, las fuerzas vinculadas a la cultura política común que, cuanto más abstracta se haga, tantas más subculturas lleva a un denominador común, tienen que seguir siendo lo suficientemente fuertes como para no permitir que se desmorone la nación de ciudadanos"23.

Por ello, y siguiendo la línea de Habermas, es necesario que el Estado permita el desarrollo de una ciudadanía en la que los individuos sean corresponsables en las diferentes decisiones políticas del ámbito público; esto, con el objetivo de despertar una conciencia solidaria, que elimine las prácticas clientelares que finalmente llevan a la apatía y a la dependencia de los individuos. En esta lógica, la ciudadanía debe estar fundada en hacer valer los derechos civiles, económicos, sociales y políticos, que se manifiestan en un doble vínculo.

\section{El patriotismo constitucional desde la globalización y la acepta- ción de las diversas formas de vida}

La mirada de un patriotismo constitucional, desde la óptica de Habermas, no puede estar situada en lo étnico, cultural o en un nacionalismo. Este patriotismo se contextualiza en los principios democráticos de una Carta constitucional que respeta los derechos humanos y confiere un estatus de ciudadano, y va más allá de la situación legal o jurídica de los individuos, como el mismo autor lo expresa:

"Por tanto, deberíamos aprender finalmente a entendernos no como una nación compuesta por miembros de una misma comunidad étnica, sino como una nación de ciudadanos (...), pues la república no tiene, en definitiva, otra estabilidad que la que le confieren las raíces que los principios de su constitución echan en las convicciones y prácticas de sus ciudadanos"24.

23 Habermas, Jürgen, Identidades nacionales y postnacionales, Tecnos, Madrid, 1989, pp. 174-175.

24 Habermas, Jürgen, La inclusión del otro. Estudios sobre teoría política, obr. cit. p. 265. 
Esto significa que el patriotismo constitucional tiene, en esencia, la aceptación de diversas formas de vida y culturas, las que tienen cabida en el contexto de una república que no excluye -dado que es pluralista y abierta a diferentes formas de mestizaje- reforzando el sentimiento de pertenencia a una ciudadanía inclusiva y participativa. Este proceso se ve consolidado por el fenómeno de la globalización, que exige, para poder ser viable, una identidad postnacional, que pueda incluir valores de corte universal que trasciendan la propia cultura. Para hacer posible este proceso, la cultura mayoritaria debe desprenderse de su situación histórica excluyente, logrando así la identificación de todos los ciudadanos con la cultura política de su país. Esta desvinculación de la cultura política de la cultura mayoritaria permite la solidaridad de los ciudadanos.

\section{El patriotismo constitucional y el problema de la identidad en Habermas}

La respuesta que pretende dar el patriotismo constitucional respecto a este punto, es cómo dotar de una nueva identidad colectiva a la comunidad política (cuya historia ha experimentado el conflicto y la ruptura), además de intentar la búsqueda de las características identitarias compartidas en una sociedad pluralista culturalmente. Teniendo en consideración estos puntos, es importante el planteamiento de Habermas sobre la racionalidad práctica, que cumple tres usos bien diferenciados: un uso moral, un uso ético y por último uno pragmático.

Digamos que el discurso de la identidad, desde una perspectiva individual como colectiva, responde a un discurso ético, lo que obliga a que siempre tenga una validación de tipo contextual, por sobre una validación de tipo universal. En este sentido, el patriotismo constitucional de Habermas, sería una respuesta a una identidad colectiva más amplia, que pueda incluir a los ciudadanos de una sociedad compleja y diversa. En este aspecto Habermas ${ }^{25}$ sostiene que los procesos de diferenciación social obligan al individuo a desempeñar diferentes roles en la vida (de tipo asociativo, en el trabajo, en el vecindario, etc.), por lo cual asume distintas pertenencias, puesto que la identidad no es algo determinado e inmutable. Así, la identidad individual no necesariamente coincide con la construcción social e intersubjetiva de la identidad colectiva, pero sí es complementaria. El mismo Habermas lo afirma cuando dice que: "Sería falso representar las identidades grupales como 'identidades del yo' en gran formato; entre ambas no se da ninguna analogía, sino tan solo una relación de complementariedad"26. Los individuos, a juicio de Habermas, no estarían sujetos a un único código de cultura, sino que de acuerdo a las circunstancias optarían por uno u otro.

25 Habermas, Jürgen, Teoría de la acción comunicativa, Taurus, Madrid, 1987, p. 86.

26 Habermas, Jürgen, Identidades nacionales y postnacionales, obr. cit. pp. 100-101. 
Jorge Araya Anabalón

Pese a todo, Habermas sostiene que la nación representa una "forma específicamente moderna de identidad colectiva" ${ }^{27}$, pues si bien responde a una tradición histórica, de igual forma obliga a que de manera consciente se trascienda la supuesta comunidad natural. De tal forma la nación respondería a, la sangre y la tierra, lo que daría un primer paso de apropiación en forma reflexiva de las tradiciones de las que los individuos se consideran parte. Hay que considerar que Habermas ${ }^{28}$ plantea la posibilidad de una identidad colectiva en el marco de un proyecto profundamente democrático, y fundamentalmente de respeto de los derechos humanos. Esto implica que no debe situarse el sentimiento de pertenencia a una nación o comunidad étnico-cultural, identificada con un único destino común, por sobre la lealtad a la nación de ciudadanos (como titular de soberanía política) que nos incluye a todos. Hacer lo primero, trae como consecuencia la represión y la asimilación por medio de la coerción, con las consecuencias de violación de los derechos fundamentales de las personas por grupos religiosos, socioeconómicos y étnicos.

\section{El pluralismo cultural en el contexto del patriotismo constitu- cional}

Para Habermas, el pluralismo es posible en una cultura política republicana que permita cohesionar a una sociedad, con el respeto a las diferentes formas de vida y tradiciones culturales heterogéneas. Así se articularía, democráticamente, una sociedad multicultural, donde la identidad colectiva tendría que poseer las características de supranacional o postnacional, permitiendo la compatibilidad con un pluralismo que contenga las identidades nacionales.

De ahí que el patriotismo constitucional debe fundamentarse en un régimen político democrático y no en los conceptos de los sustratos prepolíticos de una comunidad étnico-nacional. Habermas da como argumento que: "sociedades multiculturales como Suiza y los Estados Unidos muestran que una cultura política en la que puedan echar raíces los principios constitucionales no tienen por qué apoyarse sobre un origen étnico, lingüístico y cultural. Una cultura política liberal constituye solo un denominador común de un patriotismo constitucional que agudiza el sentido de la multiplicidad y de la integridad de las distintas formas de vida coexistentes en una sociedad multicultural"29. Este planteamiento de Habermas, será posible si se construye un sentido fuerte de ciudadanía, junto a un uso ético de la razón práctica, cuya fuerza reside en el poder comunicativo que se ejerce en los espacios públicos, y que es parte de la competencia ciudadana.

\footnotetext{
Habermas, Jürgen, Identidades nacionales y postnacionales, obr. cit. p. 89.

Habermas, Jürgen, Pensamiento postmetafísico, Taurus, Madrid, 1990, p. 310.

29 Habermas, Jürgen, Facticidad y validez. Sobre el derecho y el Estado democrático de derecho en términos de teoría del discurso, obr. cit. p. 628.
} 


\section{Alcances del patriotismo constitucional versus nacionalismo en el caso de Chile}

En la mayoría de los países latinoamericanos se confunde el concepto de patriotismo nacionalista con el de "patriotismo constitucional". Este último busca la inclusión del "otro", la igualdad, la equidad y el reconocimiento de sus derechos desde una perspectiva de solidaridad entre los ciudadanos que defiende los valores comunes del sistema democrático.

En el patriotismo nacionalista, los resultados han sido desastrosos y sus consecuencias se han traducido en guerras, golpes militares e ingobernabilidad política, lo que a su vez han acentuado la exclusión y el racismo en el caso de América Latina. Estos aspectos se afirman en las concepciones militares de los distintos países respecto a cierta superioridad racial, en lo cual Chile no ha sido la excepción.

Ahora, la propuesta de un "patriotismo constitucional", tiene como fundamento la inclusión de todos los ciudadanos a partir de un pluralismo que comprenda los ámbitos cultural y jurídico, y que pasa necesariamente por una constitución democrática que contemple dichos derechos. En el caso particular de Chile, debemos considerar un patriotismo basado en una concepción nacionalista, que excluye toda diferencia en favor de una visión histórica militarista homogénea, situación que produce una oposición con los pueblos indígenas. Dicha concepción del patriotismo es lo que ha excluido a los pueblos originarios y ha permitido la usurpación de sus tierras, infringiéndoles una derrota político militar. Así, el patriotismo de la Constitución en Chile, no acepta en la práctica la heterogeneidad, multiculturalidad e interculturalidad, dado que entiende que desarrollar dichas concepciones fragmentaría la sociedad nacional. De esta realidad se desprende, que no existe reconocimiento del "otro" en la política, lo que significaría la inclusión del derecho de su alteridad, que es el derecho a la diferencia.

\section{Bibliografía}

Amengual Coll, Gabriel, La solidaridad según Jürgen Habermas /en/ Cuadernos Salmantinos de Filosofía, №19, 1992.

Cortina Orts, Adela, Ética sin moral, Tecnos, Madrid, 1990.

Cortina Orts, Adela, Ética aplicada y democracia radical, Tecnos, Madrid, 1993.

Cortina Orts, Adela, Alianza y contrato, política ética y religión, Trotta, Madrid, 2001.

Habermas, JÜrgen, Teoría de la acción comunicativa, Taurus, Madrid, 1987.

Habermas, Jürgen, Identidades nacionales y postnacionales, Tecnos, Madrid, 1989. 
Habermas, Jürgen, Historia y crítica de la opinión pública, G. Gilli, Barcelona, 1990.

Habermas, Jürgen, Pensamiento postmetafísico, Taurus, Madrid, 1990.

Habermas, Jürgen, Escritos sobre moralidad y eticidad, Paidós / ICE-UAB, Barcelona, 1991.

Habermas, Jürgen, La modernidad, un proyecto inacabado, en F. Viviescas y F. Giraldo (eds.), Colombia: el despertar de la modernidad, Bogotá, 1991.

Habermas, Jürgen, Sobre el desarrollo de las ciencias sociales y las ciencias del espíritu en la República Federal de Alemania, en J. Pérez (ed), Textos y Contextos, Ariel, Barcelona, 1995.

Habermas, Jürgen, Facticidad y validez. Sobre el derecho y el Estado democrático de derecho en términos de teoría del discurso, Trotta, Madrid, 1998.

Habermas, Jürgen, Conciencia moral y acción comunicativa, Península, Barcelona, 1998.

Habermas, Jürgen, La inclusión del otro. Estudios sobre teoría política, Paidós, Barcelona, 1999.

Habermas, Jürgen, Ensayos políticos, Península, Barcelona, 2000.

Habermas, JÜrgen, La constelación postnacional, Paidós, Barcelona, 2000.

Habermas, Jürgen, Facticidad y Validez: Sobre el Derecho y el Estado Democrático de Derecho en Términos de Teoría del Discurso, Trotta, Madrid, 2000.

Pérez Tapias, José, El riesgo de opinar, Comares, Granada, 2006.

98 Revista Chilena de Derecho y Ciencia Política - Vol. 3, No 1, Año 2, 2011 